\title{
Different Ways of Viewing an Organization
}

\begin{abstract}
From the industrial revolution to the present, scholars, consultants and experts in different disciplines have tried to answer the fundamental question: What is a business? In this chapter, we structure these historical perspectives in the following groups: Mechanical, Organic and Cultural. The mechanical perspective provides the "rational logic" of planning and supervision. The organic perspective adds creativity and initiative. Finally, the cultural perspective promotes internal unity through a common purpose that harnesses the commitment and engagement of the company's members. From the combination of the three perspectives, we introduce the "Integrated Organizational Model" as the conceptual foundation of management by missions (MBM).
\end{abstract}

Keywords Organizational logics • Organization • Management

- Purpose

The sponsors are: DPMC Foundation \& Chair in Management by Missions and Corporate Purpose (UIC) 
From the industrial revolution to the present, different theories and approaches to management have emerged. Scholars, consultants, managers from the business world and experts in disciplines from psychology to engineering have tried for decades to answer the fundamental question: What is a business? The idea or conceptual model of business has a major influence on the development of any management system. Given this, we need to base our management system proposal on a solid conceptual model.

Over time, theories and social trends have provided different perspectives that shape the understanding of a business in today's management world. These different perspectives (or logics) transcend a specific organization and apply to all companies. ${ }^{1}$ Following the approaches of Juan Antonio Pérez López, ${ }^{2}$ which have helped to inform this book, these perspectives can be classified, in chronological order, in the following groups: ${ }^{3}$

- Mechanical Perspective. Seeing the company as a "machine" that must be managed "scientifically" through what we might call the rationalism of planning and control.

- Organic Perspective. Seeing the company as a "living organism" that has initiative and creativity, and that must be managed based on people's performance and talent.

- Cultural Perspective. Seeing the company as a "social organization" that has ends and values, whose management must create a culture that ensures commitment and unity among its members.

\section{Mechanical Perspective}

In the late nineteenth and twentieth centuries, initiatives and theories based on rationalism flourished, giving rise to what is known as "scientific management." The main contributors were the German sociologist Max

\footnotetext{
${ }^{1}$ M.S. Dijksterhuis, F.A. Van den Bosch and H.W. Volberda, "Where Do New Organizational Forms Come From? Management Logics as a Source of Coevolution," Organization Science, vol. 10, no. 5, 1999, pp. 569-582.

${ }^{2}$ Juan Antonio Pérez López, Paradigmas del liderazgo, Rialp, Madrid, 1991.

${ }^{3}$ These three perspectives correspond to what Juan Antonio Pérez López called mechanistic, psychosocial and anthropological.
} 
Weber and the American engineer Frederic Taylor. Weber affirmed that bureaucracy was the most efficient form of human organization, while Taylor demonstrated that people's activity could be studied systematically and broken down into its elementary parts. In Taylor's view, managing a company consisted basically of planning and supervising activities. "Each worker's task must be fully planned, and each person must receive written instructions that describe to the minute the details of the work to be performed, as well as the means to use to achieve it."

During the first half of the twentieth century, Taylor's ideas spread throughout the world and were introduced to Europe by experts such as Urwick, in the United Kingdom, and Fayol, in France. Fayol, in fact, developed a definition that captures the perspective of his contemporaries: "To manage is to forecast and plan, to organize, to command, to coordinate, and to control."

Theoretical assumptions gave way to a number of management tools throughout the twentieth century. Some of the most widespread examples that have survived to this day notably include budgeting systems, job descriptions, strategic planning models of the 1970s and the reengineering of processes of the 1990s.

This "rationalistic" viewpoint focuses on the basic elements of what we have called the mechanical perspective (see Fig. 2.1). Those elements are strategy, systems and structure that reinforce and enrich each other According to this perspective, managing a company consists of (1) developing a good strategy; (2) implementing it appropriately through certain processes (manuals, procedures, policies, rules...) and (3) efficiently using the structure (resources and capacities). A company's profitability return and financial health, and also its capacity to undertake new strategies in the future, will depend on how successfully these three elements

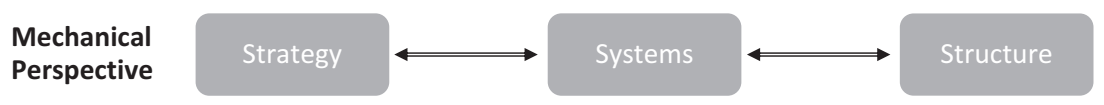

Fig. 2.1 Mechanical perspective

\footnotetext{
${ }^{4}$ F.W. Taylor, The Principles of Scientific Management, Harper \& Row, New York, 1915.

${ }^{5}$ H. Fayol, General and Industrial Management, Pitman Publishing, London, 1949.
} 
are administered and aligned. For decades, this simple and direct way of understanding the corporation was the basis for management techniques and models.

This perspective corresponds to what we can call the management by tasks characterized by the "command and control" type of manager, who manages people through strict tasks and role assignments. This way of managing people has some advantages: it is orderly and well planned, and in certain environments even efficient. However, it has major shortcomings. For one thing, it smothers initiative and creativity, such that people perform well below their capability.

\section{Organic Perspective}

In the 1930s, Harvard psychologist Elton May (1880-1949) was researching the influence of certain external factors on worker productivity. The best-known example is the study of lighting conditions in Western Electric's Hawthorne plant. First, Mayo increased the light intensity in the workplace and observed that productivity increased. Subsequently, he decreased the light intensity and observed that productivity again increased. What was happening?

For a decade, Mayo conducted numerous similar studies with equally disconcerting results. In the end, he put forward a theory-the simple fact of paying attention to workers, and asking them to take part in something they felt was important, greatly influenced their productivity. Mayo's experiments opened up a new line of psychologically based research and development, in which people were seen as the decisive factor in a companies' success.

Following a similar approach, one of the most important contributions after the Second World War was Douglas McGregor's theory X and theory Y. ${ }^{6}$ Each of these two theories gave a very different view of the worker. While theory X states that the worker is lazy and needs constant supervision, theory $\mathrm{Y}$ says that the worker is capable of being creative and

\footnotetext{
${ }^{6}$ D. McGregor, The Human Side of Enterprise, McGraw-Hill, New York, 1960.
} 
innovative and will naturally seek responsibility. Through these two theories, McGregor called into question the idea that planning and supervision are the determining factors for a company's success.

In the second half of the twentieth century, under the influence of this idea, human resources began to take on an increasingly influential role and we saw the word "labor" change to "talent." That is because, although some human activity can be planned and controlled (formal activity), most of the work people do depends on initiative and creativity, and requires deeper personal involvement (qualitative activity).

Nowadays, automation and new technology have taken over most of the formal activity. As a result, fewer workers now perform purely repetitive tasks. A growing number of jobs add value through qualitative insight. The more complex the environment and the organization, the greater the need to provide an outlet for members' initiative and creativity while creating an attractive work environment (workplace climate), in which people can realize their full potential.

Based on the experience of successful companies, Pfeffer, in his book The Human Equation, ${ }^{7}$ lists seven key people management practices for reaching the people's full potential: job security, selective hiring, decentralized decision-making, contingent compensation, extensive training, reduction of status differences and sharing of financial and performance information. Pfeffer stresses that, for these practices to be effective, they must be consistent with one another and with the company's strategy.

Companies today are making serious efforts to create a pleasant work climate for their people. Successful practices include the following:

- Active participation of all employees. Hilton promotes the notion that all employees are important to the company. This allows new ideas to filter through the organization, making it more adaptable.

- Proximity of the leaders. Facebook executives (including its CEO and co-founder Mark Zuckerberg) work in open spaces alongside other employees to promote a sense of equality.

- Work and fun. Google strives to keep its employees happy and productive. Its offices include a wide range of services, including free 
meals, access to the gym, recreational spaces and sleep pods for taking a nap.

- Diversity and inclusion. At Zappos (an online retailer of shoes, clothing and accessories), employees are encouraged to express themselves freely and be authentic through various measures, such as the freedom to decorate their workspace.

- Flexible work schedule. All Netflix employees are asked to be autonomous and manage their own schedule; they are judged not by their hours worked, but by their skills and achievements.

- Hiring policies. At Whole Foods Market, employees must be voted in by their future coworkers to become permanent hires. The main criterion for hiring is "People who know how to treat people."

This new approach, where business management is people-centric, constitutes what we call the "organic perspective" (see Fig. 2.2). The organic perspective adds three fundamental elements to management: talent, management systems and people's specific contribution (goals and results). Giving people scope for initiative and creativity creates an organizational context that is richer but also more complex. One of the first such management systems to be introduced was management by objectives (MBO), proposed by Peter Drucker in $1954 .{ }^{8} \mathrm{MBO}$ is "a process whereby the superior and subordinate managers of an organization jointly identify its common goals, define each individual's major areas of responsibility in terms of the results expected of him, and use these measures as guides for operating the unit and assessing the contribution of each of its members."

Under MBO, each employee works in a context defined by objectives, for which they are responsible and which they accept as challenges. The

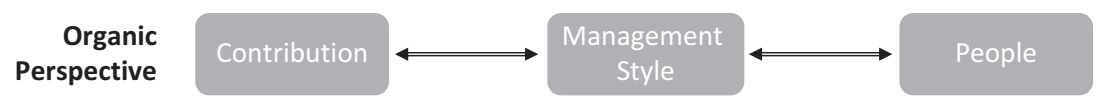

Fig. 2.2 Organic perspective

\footnotetext{
${ }^{8}$ Peter Drucker, The Practice of Management, Harper \& Row, New York, 1954, ch. 11: "Management by Objectives and Self-Control."

${ }^{9}$ George S. Odiorne, Management by Objectives, Pitman Publishing, London, 1965, p. 56.
} 
worker takes a proactive attitude toward achieving the objective. Unlike "management by tasks," the focus of management is no longer on the tasks but on the results. This encourages managers to concentrate their efforts on the few activities that are capable of producing significant business results. ${ }^{10}$

Later, as a complement to $\mathrm{MBO}$, came the philosophy of "empowerment": a context of autonomy and motivation, encouraging people to use creativity and initiative. Edward E. Lawler, one of the main proponents of this management style, defines empowerment in four dimensions: ${ }^{11}$ power, information, rewards and knowledge (PIRK). Power consists of ensuring that people have sufficient power and resources to meet their targets. Information consists of giving people the information they need in order to achieve their objectives. Rewards have to do with the benefits and rewards workers may obtain if they accomplish their objectives. Knowledge consists of helping employees to acquire the knowledge and skills to do their job successfully.

\section{Cultural Perspective}

In the early 1980s, after a decade marked by the oil crisis, poor business performance and increasing competition worldwide, managers were looking for new ideas and solutions. Among the various currents of management thought prevailing at the time, three books caught the attention of practitioners and scholars: William Ouchi's Theory $Z,{ }^{12}$ Pascale and Athos's The Art of Japanese Management ${ }^{13}$ and Peters and Waterman's In Search of Excellence. ${ }^{14}$ They all became best-sellers and were very influential, and still are today.

\footnotetext{
${ }^{10}$ Peter Drucker, Managing for Results, Harper \& Row, New York, 1964.

${ }^{11}$ Edward E. Lawler, Rewarding Excellence, Jossey-Bass, San Francisco, 2000.

${ }^{12}$ William Ouchi, Theory Z: How American Business Can Meet the Japanese Challenge, AddisonWesley, 1981.

${ }^{13}$ Richard T. Pascale and Anthony G. Athos, The Art of Japanese Management, Simon and Schuster, New York, 1981.

${ }^{14}$ Thomas J. Peters and Robert H. Waterman, In Search of Excellence, Harper \& Row, New York, 1982.
} 
These and other books based on studies of the world's most successful companies revealed, among other things, something that left much of the business world perplexed: the key to lasting success does not lie in a particular strategy or efficient use of resources, but in a hitherto largely ignored dimension of management, the cultural dimension. Under this perspective, the company is nurtured by and dwells within a social context where it makes an impact that goes beyond the exchange of goods and services.

Strictly speaking, cultural theories of the corporation were not a late twentieth-century invention. A number of authors had previously written about the importance of corporate culture. The best known of them is Chester I. Barnard, who in the 1930s argued that one of the three primary functions of the executive is to formulate, define and inculcate a shared purpose that gives meaning to the organization. ${ }^{15}$ Barnard was not a theorist and cannot even be said to have developed a theory. Rather, he brought to bear his practical experience as president of AT\&T, one of the United States' leading companies. A few other companies, such as Hewlett-Packard, Johnson \& Johnson, General Electric and IBM, had similar experiences to that described by Barnard. But it was not until the 1980s that the cultural dimension started to attract serious attention in the world of management.

This current of thought is represented by what some refer to as "organizations with purpose," 16 which entails seeking meaning beyond just profit and shareholder return. ${ }^{17}$ Amid the current challenges-growing uncertainty, disruption, greater need for meaningful employment among the younger generations, digitization and so on-purpose has emerged as a key element of success. ${ }^{18}$ In a recent statement by Larry Fink, Chairman and CEO of BlackRock, the world's largest investment firm, "a company

\footnotetext{
${ }^{15}$ Chester I. Barnard, The Functions of the Executive, Harvard University Press, Cambridge, MA, 1938.

${ }^{16}$ E. Hollensbe, C. Wookey, L. Hickey, G. George and C.V. Nichols, "Organizations with Purpose," Academy of Management Journal, vol. 57, no. 5, 2014, pp. 1227-1234.

${ }^{17}$ C. Rey, M. Bastons and P. Sotok, Purpose-Driven Organizations, op. cit., p. 138.

${ }^{18}$ R.E. Quinn and A.V. Thakor, "Creating a Purpose-Driven Organization: How to get Employees to Bring Their Smarts and Energy to Work," Harvard Business Review, July-August 2018, pp. 78-86.
} 


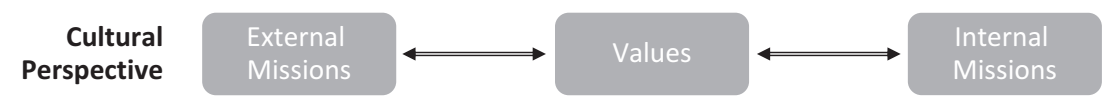

Fig. 2.3 Cultural perspective

cannot achieve long-term profits without embracing purpose and considering the needs of a broad range of stakeholders." ${ }^{19}$

This perspective introduces a new way of viewing the company, one we call the cultural perspective (see Fig. 2.3). This perspective comprises three elements, which make up the core of an organization's purpose and culture: external missions, values and internal missions. In external missions, the organization's focus is on meeting the needs of stakeholders (customers, consumers, communities). Internal missions, meanwhile, are about the stakeholders who contribute to meeting those needs (employees, suppliers, associates, shareholders). And values, as the synthesis of missions, are related to the fundamental criteria for decision-making.

These three elements are interrelated and so must be aligned in order to form a consistent culture. From the cultural perspective, a company is more than just a machine, or a group of people with initiative and creativity: it is a social institution with its own identity, defined by missions and values that are shared by its members.

The cultural perspective aims to generate what might be termed "ownership" or a sense of belonging. Ownership goes beyond empowerment. In fact, many companies that have launched empowerment programs find that the difficult thing is not giving people more power, but gaining their commitment. To do that, companies must develop a culture that inspires people to identify with a shared undertaking and shared values.

This desire for employee commitment and engagement has led to a proliferation of attempts to develop a philosophy and a set of values that give meaning to business enterprise: basically, why do companies exist? Nowadays, thousands of companies already have a formal purpose and values statement, and the trend is steadily increasing. Meanwhile,

\footnotetext{
${ }^{19}$ See: https://www.blackrock.com/corporate/investor-relations/larry-fink-ceo-letter. [Referenced: $11 / 9 / 2020]$
} 
internal communication departments and systems designed to spread the corporate identity throughout the organization have mushroomed.

Various methods of building corporate culture with purpose have emerged in recent years. These methods are based on creating models and symbols that reinforce the desired values. Under this perspective, company reputation is not just an economic issue, or even a necessity for attracting talent. It is an imperative, a reason for being, a responsibility. And naturally, all these efforts are explicitly backed by top management and reinforced by a suitable internal communication campaign.

Companies are increasingly striving to build a meaningful culture. Some of the more successful approaches include the following:

- Transparency. "There is a consistent effort to be transparent and have a diverse work culture. People are encouraged to speak up and solve problems," said a Microsoft employee. ${ }^{20}$

- Social awareness. Volunteering and community engagement are pillars of the employee experience at Salesforce.

- Reduction of status differences. Whole Foods Market instituted a salary cap for executives relative to the average pay of full-time members.

- Cultural projects. Some companies have set up inter-functional or agile groups to work on specific projects to promote the purpose and values. ${ }^{21}$

- Values-based awards. Sony gives out awards for those who embody its values most.

\section{The Integrated Organizational Model}

The three perspectives we have described are entirely complementary and necessary for any organization to develop and succeed. A company cannot be explained exclusively by any one of these perspectives; all three are required. The mechanical perspective provides the "rational logic" of planning and supervision that is needed for the company to operate. The

\footnotetext{
${ }^{20}$ See: https://www.forbes.com/sites/rachelmontanez/2019/12/10/the-best-companies-for-corporate-culture-in-2019/\#471913b96dc3. [Referenced: 11/9/2020]

${ }^{21}$ R.E. Quinn and A.V. Thakor, “Creating a Purpose-Driven Organization,” art. cit., pp. 78-85.
} 


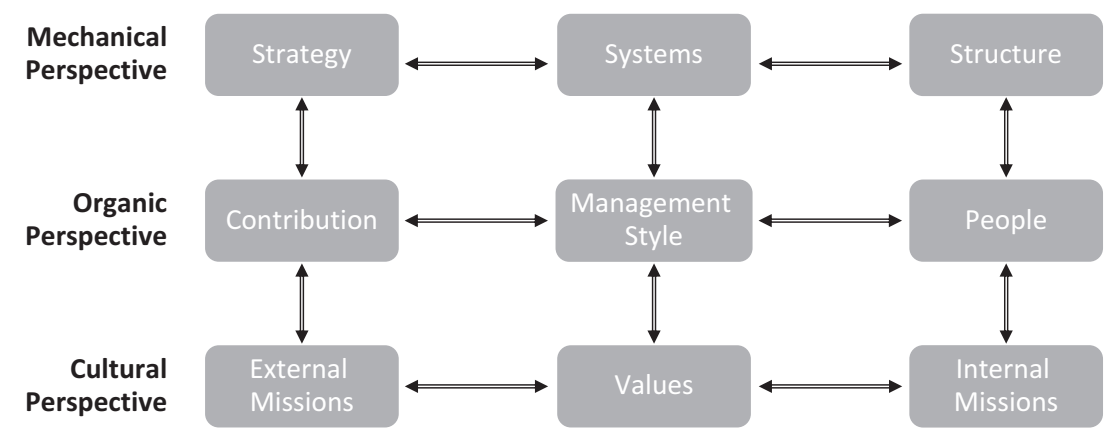

Fig. 2.4 Integrated model

organic perspective adds the creativity and initiative that takes the company beyond the limits of corporate planning. And the cultural perspective promotes internal unity through a common purpose that harnesses the commitment and engagement of the company's members.

Nonetheless, we have found that many companies that today are using the management by objectives as their primary management system integrate the mechanic and organic perspective, but are not successful in the integration of the cultural dimension in their day-to-day management. Efforts aimed at creating purpose (communication, speeches, activities, outdoor activities, awards, posters, etc.) are disengaged from the management system, creating disconnection. This leads to a dichotomy in the organization, like a split-personality disorder in which two identities function separately. This lack of alignment ultimately undermines trust and, therefore, unity.

The solution requires an integration of the three perspectives (see Fig. 2.4). This integrated model is the conceptual foundation of management by missions (MBM), that aims for a consistent and natural development of the cultural dimension in the company.

In the next chapter, we will analyze in depth the limits of management by objectives. In the following sections, we will discuss how to overcome these limits with a renewed management system.

\footnotetext{
${ }^{22}$ The technological institutes of the Valencian Community are private, nonprofit research organizations that support companies, particularly SMEs, to boost their competitiveness through RDI.
} 


\section{Beyond Business}

Since its inception, management by missions (MBM) has evolved naturally in business companies. The integration of missions and values with the other elements of the organization-strategy, systems, structures, management styles and people-provides businesses with a "soul." Also, MBM has helped a wide variety of nonprofit organizations - such as universities, governmental organizations, associations or foundations-to better integrate their "soul" into the day-to-day management. In these organizations, especially those that operate in a competitive environment, MBM provides a methodology to stay the course and be faithful to their institutional purpose.

We can see this, for example, in the case of AITEX, the Textile Industry Research Association in the Valencian Community of eastern Spain, ${ }^{22}$ which, since 2008, has subscribed to the MBM methodology. Vicente Blanes, CEO of AITEX, shares his experience:

"At AITEX, missions have really helped us to grow and manage that growth. Twelve years ago, when we started implementation, AITEX had a total of 132 employees and an operating income of $€ 12.2$ million. In 2020, we ended up with an operating income of over $€ 30$ million, 300 employees in Spain and 30 more abroad, and offices in eight countries. All this growth has happened during a wonderful period of time for us, and management by missions has been really helpful.

"If I had to write a headline for it, I would say that management by missions is about creating a breeding ground and then a system for each person in the organization to bring out the leader within them. This is definitely what moves me; it's what we do in our own lives. Why are we not able to get every person in the organization to do this when they come to work? To me, the missions are a guiding light. It has really helped us focus on our customers, teamwork, employee growth... and to provide the best, most reliable service and proximity to companies in the textile sector, which are the reason for our existence. It's helped us to decentralize decision making, create autonomous and independent units that coordinate with each other... And every step of the way, we're following that guiding light, which is our mission.

"For an organization like ours, this is essential. As a private association, we have a board of directors-our governing body-made up of over 20 CEOs of textile companies. We have multiple business units, multiple research groups, multiple lines of high value-added services, operations in multiple countries... Without clear and shared missions, this would be like an orchestra out of tune: we would not sound good. The missions fuse and harmonize our commitments with our key stakeholder groups; they unite and guide the organization. This is how we achieve our mission for companies in the textile and cosmetic industries (we recently added cosmetics), and for the territory, while still competing in the top tier of technology centers worldwide. 


\section{(continued)}

"I always tell people," adds Vicente, "that a hundred mission-oriented people amount to a hundred and fifty, whereas a hundred people who make an effort but aren't mission-oriented equate to more like sixty or seventy. In this case, energy is wasted, like friction force in physics. The difference is night and day. The key question is: How many leaders do you have in the organization? It should be at least $80 \%$ of the people. We believe in and defend the idea of bringing leadership to the entire organization. Management by missions gives us what we call 'the second pathway,' the one that goes from heart to action; it doesn't just add on, it exponentially expands the first pathway (from reason to action), which is how we contribute to the mission with our skills, talents and capabilities."

Open Access This chapter is licensed under the terms of the Creative Commons Attribution 4.0 International License (http://creativecommons.org/licenses/ by/4.0/), which permits use, sharing, adaptation, distribution and reproduction in any medium or format, as long as you give appropriate credit to the original author(s) and the source, provide a link to the Creative Commons licence and indicate if changes were made.

The images or other third party material in this chapter are included in the chapter's Creative Commons licence, unless indicated otherwise in a credit line to the material. If material is not included in the chapter's Creative Commons licence and your intended use is not permitted by statutory regulation or exceeds the permitted use, you will need to obtain permission directly from the copyright holder.
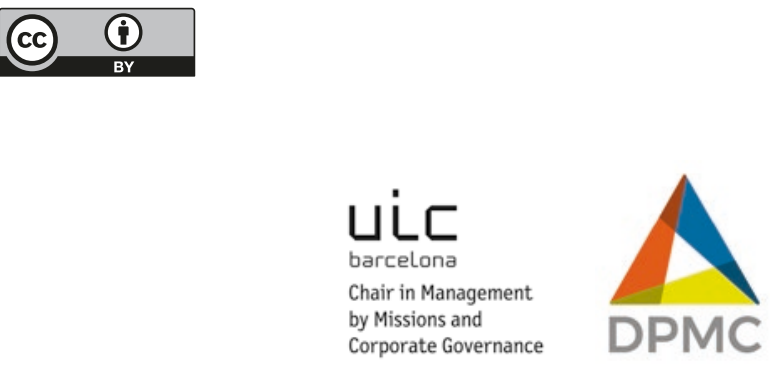